\title{
The misidentification syndromes as mindreading disorders
}

\author{
William Hirstein \\ Elmhurst College, Elmhurst, IL, USA
}

\begin{abstract}
The patient with Capgras' syndrome claims that people very familiar to him have been replaced by impostors. I argue that this disorder is due to the destruction of a representation that the patient has of the mind of the familiar person. This creates the appearance of a familiar body and face, but without the familiar personality, beliefs, and thoughts. The posterior site of damage in Capgras' is often reported to be the temporoparietal junction, an area that has a role in the mindreading system, a connected system of cortical areas that allow us to attribute mental states to others. Just as the Capgras' patient claims that that man is not his father, the patient with asomatognosia claims that his arm is not really his. A similar account applies here, in that a nearby brain area, the supramarginal gyrus, is damaged. This area works in concert with the temporoparietal junction and other areas to produce a large representation of a mind inside a body situated in an environment. Damage to the mind-representing part of this system (coupled with damage to executive processes in the prefrontal lobes) causes Capgras' syndrome, whereas damage to the body-representing part of this system (also coupled with executive damage) causes asomatognosia.
\end{abstract}

Keywords: Capgras' syndrome; Misidentification; Asomatognosia; Theory of mind; Mindreading; Executive processes.

\section{INTRODUCTION}

Capgras' syndrome is a misidentification disorder in which people deny the identities of people close to them, claiming that they have been replaced by impostors. Patients with anosognosia deny having a disability that they obviously have, and may even deny that an injured arm or leg is their own, a condition called asomatognosia (or sometimes somatoparaphrenia). These are the two oddest members of the family of confabulation syndromes, and the most difficult to assimilate to what is known about the others. A comprehensive theory of confabulation that encompasses these syndromes as well as the others could shed light on some extremely puzzling responses

Correspondence should be addressed to William Hirstein, Cognitive Science Laboratory, Elmhurst College, Elmhurst, IL 60126-3296, USA. E-mail: williamh@elmhurst.edu

(C) 2009 Psychology Press, an imprint of the Taylor \& Francis Group, an Informa business http://www.psypress.com/cogneuropsychiatry

DOI: $10.1080 / 13546800903414891$ 
to brain injury. Neurologist Todd Feinberg (2001) has proposed a hypothesis designed to encompass both the misidentification syndromes and asomatognosia, according to which they are disorders of the patient's sense of personal relatedness to other people and to his own body. In the subsequent sections, I will offer an alternative to Feinberg's view that brings these two syndromes under the tent of a two-factor hypothesis of confabulation (Hirstein, 2005). I will start by briefly describing the hypothesis, and conjoining it with a definition of the term "confabulation". Aside from showing that these two syndromes fit the suggested definition of "confabulation", and its accompanying two-factor hypothesis, my point in this paper is that we can understand why people have these strange beliefs if we understand the nature of the representation systems that, when damaged, produce them.

\section{TWO-FACTOR HYPOTHESES OF CONFABULATION AND DELUSION}

In 1787, speaking of confabulatory patients with Korsakoff's amnesia, John Coakley Lettsom (1789) said, "They talk freely in the intervals of mitigation, but of things that do not exist; they describe the presence of their friends, as if they saw realities, and reason tolerably clearly upon false premises." One year later, speaking of Cotard's syndrome patients (see later), Charles Bonnet said, "They usually draw apparently logical conclusions unfortunately on a completely unsubstantiated premise" (cited in Förstl \& Beats, 1992). Both quotations imply a distinction between the "premises" of the reasoning process and that process itself. Perception and the memory store supply the premises for cognition, which then operates on them to produce effective actions. Indeed, one might argue that folk psychology itself, our everyday way of describing our minds, contains this distinction, since it applies separate concepts to perception and memory on the one hand (see, hear, feel, recall) and cognition on the other (think, decide, plan). Maher (1988) has a modern version of the accounts of Bonnet and Lettsom, arguing that certain delusions are false beliefs produced by a normal response to strange experiences. There is a powerful objection to this approach, however: Why doesn't the person simply use his ability to reason to reject the strange experience? We all experience strange thoughts on occasion, the feeling that someone is watching us; the odd notion that we had a causal influence on something where no reasonable physical explanation is available (e.g., I flip a light switch and a car horn honks outside); the idea that others can read our thoughts. But we are able to reject these, and not let them establish themselves as beliefs because we have the cognitive processes required to assess their plausibility. So it seems that in order for such thoughts 
to become beliefs, there needs to be a second problem at the cognitive level. A two-factor hypothesis of delusions finds its first full explicit form in 2000 (Langdon \& Coltheart), followed a year later by a more general version of the hypothesis (Davies, Coltheart, Langdon, \& Breen, 2001). More recently, Coltheart (2007) describes in greater detail the nature of the executive problems leading to the failure to reject anomalous beliefs. Those authors were focusing on delusions, but confabulation and delusion are closely related, at least in some syndromes, including Capgras' and asomatognosia. Confabulation and delusion cannot be entirely equated, since a confabulation is a claim made by person, whereas a delusion is a mental state, typically thought of as a belief. However, a confabulation can be made on the basis of a delusion, and this seems to be what happens in the case of Capgras' syndrome. The patient has the delusion that his father, for example, is an impostor, then produces a confabulation when he explicitly makes that claim. Metcalf, Langdon, and Coltheart (2007) broached the idea that a single, common monitoring framework fails at the second phase in both confabulation and delusion. Turner and Coltheart (2010 this issue) provide convincing evidence for this hypothesis.

Contemporary writers attempting to construct a definition of "confabulation" have despaired of the fact that some of the classical syndromes involve memory disorders (Korsakoff's, and a similar syndrome: aneurysm of the anterior communicating artery), whereas others involve problems of perception (anosognosia, split-brain syndrome, the misidentification disorders). Since memory and perception are both knowledge domains, however, perhaps a broader sense of "confabulation" applies to knowledge itself, or more specifically, to the making of knowledge claims. According to this approach, to confabulate is to confidently make an ill-grounded (and hence probably false) claim that one should know, but does not know, is illgrounded (Hirstein, 2005). So envisaged, the confabulation syndromes do form a natural category, which can be further specified. Confabulations are the result of two different phases of error. The first occurs in one of the brain's epistemic systems, either mnemonic or perceptual. This produces an ill-grounded memory or perception. These malfunctioning perceptual or mnemonic processes tend to be located in the back half of the brain's cortex, in the temporal or parietal lobes. Second, even with plenty of time to assess the situation and with urging from doctors, therapists, and relatives, the patient fails to realise that his claim is flawed, due to a malfunction of higher level brain processes known collectively as executive processes, located in the prefrontal lobes. Nonconfabulating brains sometimes create flawed perceptions or memories, but we are able to correct them, using these executive processes. If I ask you whether you have ever seen the Eiffel Tower, for instance, your brain is happy to provide an image of the Tower, even if you've never been near it. But you are able to reject this as a real memory 
because you catch the mistake at the second phase before claiming that you have seen the Tower. Thus, the typical aetiology of confabulation involves damage in the posterior of the brain to some perceptual or mnemonic process, causing the first error stage, coupled with damage to some prefrontal process, causing the second error stage. The two events of damage need not occur at the same time; there are numerous cases in the literature in which patients with an existing site of brain damage began confabulating after damage to a second site.

If we understand confabulation as an epistemic problem then, the confabulation syndromes can be categorised as disorders of the brain's knowledge domains:

1. Knowledge of the body and its surroundings: anosognosia.

2. Knowledge of recent events involving oneself, i.e., autobiographical memories: Korsakoff's syndrome, anterior communicating artery syndrome.

3. Knowledge of other people: the misidentification syndromes.

4. Knowledge of our minds: split-brain syndrome.

5. Knowledge derived from visual perception: Anton's syndrome (denial of blindness).

Stated in terms of individually testable criteria, the recommended definition of "confabulation" is: S confabulates (that $p$ ) if and only if (Hirstein, 2005):

1. S claims that $p$.

2. $\mathrm{S}$ believes that $p$.

3. S thought that $p$ is ill-grounded.

4. S does not know that her thought is ill-grounded.

5. S should know that her thought is ill-grounded.

6. $\mathrm{S}$ is confident that $p$.

The concept of claiming (rather than, for instance, saying or asserting) is broad enough to cover a wide variety of responses, including nonverbal responses such as drawing or pointing. The second criterion captures the sincerity of confabulators: They are not lying, and if explicitly asked, "Do you believe that $p$ ?" they will answer affirmatively. The third criterion refers to the problem that caused the flawed response to be generated in the first place (the first factor): Processes within the relevant knowledge domain were not acting optimally. The fourth criterion refers to a cognitive failure at a second phase (the second factor), the failure to check and reject the flawed response. The fifth criterion captures a normative element in our concept of confabulation: If the confabulator's brain were functioning properly, she would know that the claim is ill-grounded, and not make it. The claims made 
are about things any normal person would easily get right. This criterion also prevents the definition from applying too broadly. We do not consider theologians to be confabulating, for instance, even though their claims sometimes seem to be made on the basis of little evidence, because we do not expect people to know the answers to their questions. We do, however, expect people to know whether they can see, or move their arms, and we expect them to be able to recognise people they know. The sixth and last criterion refers to another important characteristic of confabulators routinely observed in the clinic: the serene certainty they have in their claims, even in the face of obvious disbelief by their listeners (see Langdon \& Bayne, 2010 this issue, who discuss a similar quality of subjective certainty in patients with delusions). Research from multiple groups indicates that there may be an additional component at work in at least some cases of confabulation: The confabulator has a motive to believe that $p$ (Feinberg, 2009; Fotopoulou, 2009, 2010 this issue; McKay \& Kinsbourne, 2010 this issue).

This epistemic approach eliminates a problem endemic to the falsity criterion in the original; narrower definition of "confabulation", according to which confabulations are false memory reports (Berlyne, 1972). If a patient answers correctly, but out of luck, we still consider her to be confabulating. The problem is not the falsity of the patients' claims but rather their ill-groundedness and unreliability, at least in the affected domain. In shorter form then, in this epistemic view, to confabulate is to confidently make an ill-grounded claim that one should know, but does not know, is ill-grounded.

\section{Capgras' syndrome}

Neurological patients with Capgras' syndrome claim that people close to them, typically spouses, parents, or children, have been replaced by similarlooking impostors. When asked how they can tell that the person is an impostor, Capgras' patients will often confabulate. One patient claimed that she could tell her husband had been replaced because the new person tied his shoelaces differently; another patient said that the impostor of her son "had different-colored eyes, was not as big and brawny, and that her real son would not kiss her" (Frazer \& Roberts, 1994, p. 557). A blind Capgras' patient said that the impostor's hand felt softer than his mother's (Rojo, Caballero, Iruela, \& Baca, 1991). The patient's attitude towards the "impostor" can vary. The majority of Capgras' patients are suspicious of the "impostor" at the very least. Many are paranoid about the "impostor", and attribute intent to harm to him, but there are also cases where the patient's attitude is positive. Capgras' syndrome patients will sometimes even misidentify themselves as seen in photos, or even in a mirror (Hirstein 
\& Ramachandran, 1997; Silva \& Leong, 1994, review 30 cases of Capgras' for oneself). Capgras' syndrome fits the pattern of damage seen in the memory syndromes: damage to some knowledge system, in this case a perceptual one, paired with frontal damage (Signer, 1994).

\section{Asomatognosia}

"Anosognosia" means lack of knowledge, or unawareness, of illness. First described in detail by Babinski in 1914, this unawareness can accompany certain types of paralysis caused by damage to the right inferior parietal cortex, and seems to play a role in causing an intriguing response known as denial in some patients. When asked about their disabilities, they will calmly and firmly deny that they are paralysed or weakened. The typical denial patient, interviewed as he rests in bed after a stroke that has paralysed his left arm, will claim that both arms are fine. When asked to touch the doctor's nose with his left arm the patient will move his torso slightly, then stop. When asked whether they touched the doctor's nose, some patients will say that they did; others will admit that they didn't but confabulate a reason why, such as that they are tired, don't feel like following commands right now, always had a weak left arm, and so on. Some of these patients will further deny that their brain injury has hampered or limited them in any way.

Although there is evidence that some anosognosic patients have some types of somatosensation, typically important higher level somatosensory areas are damaged. These posterior areas of damage, especially in the inferior parietal cortex, create the first malfunction needed for confabulation, but until recently no clear pattern of frontal damage had emerged in the study of anosognosia. In 2005, however, Berti et al. showed that patients who denied paralysis differed from those with paralysis but no denial in that the denial patients had additional damage in the frontal portions of a large brain network involved in the planning of motor actions. These frontal areas are directly connected to the damaged inferior parietal areas. Apparently, the frontal areas are capable of monitoring representations of intended actions generated by posterior areas in the same network. As Berti and her colleagues say, "monitoring systems may be implemented within the same cortical network that is responsible for the primary function that has to be monitored" (p. 488). Davies, Davies, and Coltheart (2005) contains a sustained defence of a two-factor hypothesis applied to all types of anosognosia.

Asomatognosia is regarded as a subtype of anosognosia. Patients with this syndrome will deny ownership of their own limbs. The patient will typically confabulate that the limb belongs to the doctor, or sometimes to a spouse or relative. They may claim that the arm "belongs to a fellow patient 
previously transported by ambulance, or that it had been forgotten in bed by a previous patient" (Bisiach \& Geminiani, 1991). Patients tend not to elaborate these claims into more coherent stories, about how exactly a limb came to be left in bed, for instance, and they may stop responding and turn away if pressed further. The arm involved is almost always the left arm, and asomatognosia also occurs at a high frequency among patients whose right hemisphere is temporarily anaesthetised. Feinberg and his colleagues tested 12 patients with right hemisphere stroke damage for asomatognosia, by holding up the patient's left hand so that it was visible to him and asking, "What is this?" (Feinberg, Haber, \& Leeds, 1990). The most common misidentification was calling the limb "your [the doctor's] hand", or "your arm". One patient referred to her limb as "a breast" and a "deodorant". One patient called it "my mother-in-law's" hand (Feinberg et al., 1990). Another patient called his arm a piece of "dead wood" (Weinstein, 1991); yet another called his "a piece of dead meat" (Critchley, 1974). "The idea that the arm is 'dead' in some sense, literally or figuratively, is common in anosognosia" according to Feinberg (2006, p. 75). Some patients claim that their flesh is rotting away (Fine, 2006). As Feinberg notes, asomatognosia may be regarded as a species of misidentification, in that the patients fail to acknowledge the true identity of their own arms.

Theories of the crucial neural locus for asomatognosia have focused on the inferior parietal lobes, particularly on the right side. The inferior parietal lobes are constituted by two gyri, the supramarginal gyrus (Brodmann's Area 40) and the angular gyrus (Brodmann's Area 39). Nielsen was the first to argue, in 1938, that the crucial site of damage leading to asomatognosia is the right supramarginal gyrus or its connections to subcortical areas. The study mentioned earlier by Feinberg et al. (1990) involving 12 asomatognosic patients supported this localisation.

\section{THREE HYPOTHESES}

In the cases of both Capgras' syndrome and asomatognosia, something very close and very familiar, a loved one or a body part, is claimed to be distant and unfamiliar. Jacques Vié (1930) was the first to explicitly mention this similarity (Feinberg \& Roane, 1997). In this section, I will examine three candidate explanations for the misidentification syndromes and asomatognosia. According to what is known as the affective responsiveness hypothesis of Capgras' syndrome, the patient fails to experience the normal affective reaction to the sight of a familiar person, and this causes him to form the belief that the person is an impostor. This hypothesis seems to originate with Capgras' and Reboul-Lachaux's seminal article, in which they write, "the delusion of doubles is not ... really a sensory delusion, but rather the 
conclusion of an emotional judgment" (1923/1994). Many subsequent writers have argued that in Capgras' syndrome there is a disconnection between the representation of a face and what Ellis and Young refer to as "the evocation of affective memories" (1990, p. 243) (see also Bauer, 1986; Hirstein \& Ramachandran, 1997; Staton, Brumback, \& Wilson, 1982). The patients recognise a face, but do not feel the expected emotions, and confabulate to explain this: "When patients find themselves in such a conflict (that is, receiving some information which indicates the face in front of them belongs to $\mathrm{X}$, but not receiving confirmation of this), they may adopt some sort of rationalisation strategy in which the individual before them is deemed to be an impostor, a dummy, a robot, or whatever extant technology may suggest" (Ellis \& Young, 1990, p. 244).

What is the link, however, between the absence of an emotion and the creation of the impostor story? Why doesn't the patient merely say that people seem strange or unfamiliar to him? Stone and Young (1997, p. 344) add another ingredient, the patient's prior personality, suggesting that once the patient loses the normal affective reaction to faces and, "because of a coexisting suspicious mood, or maybe a premorbid disposition, the person arrives at the idea that the source of these strange experiences must lie in a change in the external world, and the possibility of some kind of a trick, perhaps involving a substitution presents itself". But why would so many different patients with different personalities, and different premorbid dispositions arrive at the same highly unlikely story about the same trick? It is also hard to see how the affective responsiveness hypothesis could be applied to asomatognosia (something its authors have not attempted). When applied to asomatognosia, the affective responsiveness hypothesis would generate the claim that we normally experience an affective reaction at the sight of our own arms, then confabulate that the arm is not our own in order to explain the absence of this reaction, which seems implausible.

The second hypothesis is the personal relatedness hypothesis of Feinberg. The Capgras' patient has lost his sense of personal relatedness to his father, while the asomatognosic has lost his sense of personal relatedness to his arm. "Asomatognosia can be understood as a Capgras syndrome for the arm in which the personal relationship with the body part is lost" (Feinberg, DeLuca, Giacino, Roane, \& Solms, 2005, p. 103). Feinberg points out an intriguing asymmetry between Capgras' and asomatognosia on one hand, and another misidentification syndrome, Frégoli's syndrome. A patient with this syndrome will claim that a familiar person is capable of manifesting different physical appearances, so that the patients might complain that a certain person is following them or spying on them while taking on the outward appearance of different people. Feinberg observes that both Capgras' patients and asomatognosic patients claim that something or someone personally related to them is unfamiliar and distant, while the 
patient with Frégoli's syndrome sees unfamiliar people as familiar, or more broadly, falsely sees people as being personally related to him. Feinberg argues that the distinction between seeing something as personally related and seeing something as distant and foreign allows us to form a taxonomy of the misidentification disorders and other syndromes. As he puts it, "the essential dichotomization of these various disorders is on the basis of an alteration in personal relatedness or significance" (Feinberg \& Roane, 1997, p. 80). Syndromes such as Capgras' and asomatognosia that involve a decreased sense of relatedness in the patient "should be thought of as a disavowal, estrangement, or alienation from persons, objects, or experiences". Syndromes such as Frégoli's are on the "the opposite side of the spectrum" and "are manifestations of an over-relatedness with persons, objects, or experiences" (Feinberg \& Roane, 1997, p. 80).

Feinberg acknowledges, though, that not all patients can be described as claiming solely under- or over-relatedness to people and things. Some of them do both at the same time, with the same person. "Many of the important misidentifications seen in neurological patients actually represent a co-occurrence of both Capgras and Fregoli types of misidentifications" (1997). Many confabulations by asomatognosics, for example, do not involve the patient claiming that the arm or person is completely unrelated to him. One patient of Feinberg's said that her hands were not hers but her husband's, saying that, "He left them ... just like he left his clothes" (2006, p. 74). She believes that her hands are not her own, but nevertheless sees them as having a closeness to her. Because of this third, mixed type, Feinberg and his colleagues phrase their hypothesis in its final form thus: Syndromes such as Capgras', Frégoli's, and asomatognosia "represent either an increase, a decrease, or simultaneous increase and decrease in the patient's personal relatedness to objects, persons, places, or events in the patient's environment" (Feinberg \& Roane 1997, p. 80).

Personal relatedness might be too broad of a concept, however. A very high percentage of the representations in our brains are of things personally related to us, for obvious reasons. The entirety of episodic-autobiographical memory, for instance, contains representations of events personally related to us. There are many different ways in which we represent things, properties, and facts that are important to us. In addition to episodic memory, we use somatotopic maps to represent several different properties of our bodies, and our semantic memories contain a self-concept that knits together all sorts of biographical information about us, and is immediately connected to our concepts of people and things of significance to us. Feinberg also seems to overlook an important distinction between representing something as literally me or a part of me, e.g., my arm, and representing something as very closely related to me, e.g., a spouse. The presence of "mixed" patients, who show both an increase and a decrease in their senses of personal 
relatedness for an object or person, is also troubling, since it indicates that the patients do not line up neatly on a single personal relatedness continuum. One way to respond to these criticisms would be to further specify the types of personal relatedness involved.

The following hypothesis offers a more specific explanation of Capgras' syndrome, Frégoli's syndrome, asomatognosia, and other disorders of person and limb recognition that fits the basic two-factor approach. It provides an alternative account for why these syndromes exhibit the interesting variations in personal relatedness that Feinberg and his colleagues observed. Our brains represent people both allocentrically and egocentrically. Allocentric representations of people are viewpoint-independent representations of their external bodily features. Our representations of peoples' faces are a paradigmatic example of allocentric representations. One sign that they are viewpoint - independent is that we can recognise people from many different angles. Egocentric representations, in contrast, encode the positions of things and spaces relative to a central "ego". Our representations of the spaces we inhabit are usually egocentric; they represent the distance of objects from us, the trajectories of objects with regard to our location, the possible effects on us of nearby objects, and so on. Egocentric representations contain an intrinsic point of view, whereas allocentric representations are viewpoint independent. Egocentric representations give the ego a privileged place in the representations system, whereas a person's allocentric system can represent him as one person among many. Among the faces we are able to visually recognise is our own, usually seen in a mirror, but the same allocentric visual recognition processes are used whether we are looking at ourselves or at our friends.

When I represent you from my perspective, I am representing you allocentrically. When I represent you from your perspective, by using my brain's natural mindreading or simulation functions, I am typically representing you egocentrically. One type of egocentric representation of an agent is a (spatial) analogue representation from the unique point of view of that agent, from inside that agent's head, of processes and events within that agent's body, including that person's thoughts. We represent people egocentrically by simulating their current experiences from their points of view, I suggest. The brain achieves this with an egocentric representation system that functions to represent a mind situated in a body, which is in turn situated in an environment, according to the representational hypothesis. This egocentric representation system is responsible for part of our normal sense that we are embodied minds, moving about an environment. This system does not always represent us, however. It has two modes of functioning that we might call self-mode and other-mode. In self-mode, this system represents my mind, situated in my body, situated in my environment. When this system functions in other-mode it represents other people as 
minds situated in bodies situated in environments. In either mode, the system is egocentric; but different individuals can occupy the ego position of the system. In self-mode, I am the ego at the centre of this system; in othermode, the egocentric system represents or simulates the egocentric system of a person of interest.

The allocentric system represents people from the outside, including detailed facial representations, as well as representations of entire bodies, or characteristic modes of dress or movement. The skin seems to mark the boundary of what the allocentric system represents, whereas the mental component of the egocentric system represents events occurring inside the skin, as experienced from the point of view of that body's owner. These egocentric representations involve somatosensory representations, but also involve our awareness of our conscious perceptions, thoughts and emotions. Allocentric representations are primarily visual, but also involve auditory representations, as well as representations generated by other sense modalities.

\section{REPRESENTATIONS OF MINDS}

We read several different features of minds using several different brain processes, one of which, I suggest, is the egocentric mindreading system described here. The problem of the misidentification patients on this hypothesis is due to a failure of their brains to activate the correct egocentric representation of the person they are looking at. Once we get to know a person well, we develop an individualised egocentric representation of her mind. I will argue later that we also possess generic egocentric representations that can be applied to people we do not yet know well. These generic representations show themselves in our psychologies as character stereotypes, the loud obnoxious person, the shy, quiet person, and many more. We employ our own egocentric representation system in other-mode, or as a simulation, to understand the actions of other people. This is a variety of simulation theory (Goldman, 2006) in which an egocentric representation system is employed as an analogue model of that same system in another person. The misidentification syndromes can be understood as caused by damage to the mind-representing part of this large egocentric representation system. According to this hypothesis, both Capgras' and Frégoli's syndromes are mindreading disorders (Hirstein, 2005), due to failures of one of our mindreading systems, a set of brain processes we use to understand and predict the behaviour of others. Capgras' syndrome occurs when egocentric representations of a particular person are damaged or inaccessible and are replaced by other, incorrect representations. One piece of data that is at least consistent with the claim that malfunction exists in a system that is involved 
in representing both ourselves and others is the cooccurrence in patients of both self-misidentifications and misidentifications of others (see, e.g., Hirstein \& Ramachandran, 1997; several of the 30 patients with Capgras' for self reviewed by Silva \& Leong, 1994, also had Capgras' syndrome directed at others).

The representational hypothesis takes what the patients say seriously, unlike the other approaches which dismiss it as a convenient creation. These hypotheses do not account for why so many patients tell the same story. There is nothing specific about an absence of affective arousal, or of a sense of personal relatedness, that would lead someone to posit an impostor. But the experience of an unfamiliar mind situated within a familiar body, with a familiar face, is exactly what would lead to assertions about impostors. According to Feinberg's hypothesis, the Capgras' patient experiences a lack of a sense of personal relatedness, and this causes him to claim that the person he sees is an impostor. But the patient does not merely see someone familiar as unfamiliar, he perceives that person as having a different identity. The patient does not merely treat the "impostors" as less related than they were before; he treats them as different people. This is because he sees them as no longer having the same mind, the same motives, moods, and emotions. For example, paranoid Capgras' patients attribute evil intentions to the impostors.

To claim that someone is not in fact your father, but rather some stranger pretending to be your father, is to make a claim about the identity of that person, and also to disavow the personal relatedness of that person. Logically, the identity of someone is independent of that person's degree of personal relatedness to us, but in practicality, when the identity of loved ones is at stake, alterations in perceived identity will also involve alterations in perceived personal relatedness. Conversely, alterations in the patient's sense of personal relatedness need not also involve alternations in perceived identity. One might experience a loss in the sense of personal relatedness to a person, yet not doubt the identity of that person, even if that person is one's father, so that the person might say, "Dad seems strangely unfamiliar to me." Thus, an alteration in one's sense of personal relatedness alone is not sufficient to produce a misidentification patient. Similar logic applies to the affective responsiveness hypothesis. Failing to register a certain affective response at the sight of a person would not in itself lead one to doubt the identity of that person. One might rather think something like, "I don't love my mother as much as I used to." If I believe that the person in front of me is an impostor, however, strongly resembling my mother but with a different mind and identity, this would certainly lead me to have different affective responses. Thus, the representational hypothesis is logically prior to the other two, with greater explanatory power. 
The personal relatedness factor one sees in the misidentification syndromes may be due to the way that the egocentric system is not merely egocentric, and typically used to represent ourselves, but used also to represent people, objects, and events of personal significance. Rather than explaining the patient's beliefs by way of a malfunction in her personrepresentation systems, Feinberg attributes them partly to affective/motivational factors. The tendency of patients to cling to the delusional belief, according to Feinberg, "suggests that there is an impediment or resistance to the truth" (Feinberg et al., 2005; see also Feinberg, 2009). Feinberg posits various motivational factors as a way to explain this tenacity, but another explanation for the patients' insistence on their beliefs is that they are experiencing a distinct perception of an unfamiliar person (see also Langdon \& Bayne, 2010 this issue). This perception is coming from a normally trustworthy source, and the patients lack the ability to critically assess its groundedness. The idea that affective or motivational factors are doing the work also does not square with the frequently reported blandness of the patients. They are not shocked that a foreign arm is attached to their shoulder, or that impostors keep visiting them in the hospital.

In order to produce an accurate simulation of another person, we need an extensive and detailed representation. We need to build a complete scale model of an aeroplane in order to test it in a wind tunnel, for example, because of the holistic way in which changes in one property of the aeroplane affect others. If we change the airflow over one part of the plane, we have then changed the airflow over the parts of the plane behind this part. Similarly, we need a full model of a minded, embodied person in an environment in order to perform effective simulations of people in alternative situations. The way we know what to expect from a person is to create a simulation of him or her. This simulation should include the person's emotions. Knowing someone means knowing what makes her happy and what makes her angry, as well as how she behaves when she's angry or happy. Some types of simulations of minds can be thought of as functions from perceptions to actions. Two different people will respond differently to the same perceptions. One person may do what another person merely considers then inhibits, in the same situation. There are also cases where a perception causes a certain emotion that in turn causes an action. In order to represent these personalities, these functions, we would also need to simulate these emotions. We are not normally aware of our mind-representations as representations because we simply see ourselves as perceiving people with emotions and personalities and characters. We do not realise that we are not directly perceiving their emotions, intentions, or motives; we are reproducing them within ourselves, usually spontaneously.

One objection here is that the Capgras' patients tend to mention external features, not mental features, when asked how they can tell that the person in 
question is an impostor. I suggested earlier that Capgras' patients' claims about how they detect the imposter by slight differences in appearance might be a kind of confabulation. Breen, Caine, Coltheart, Hendy, and Roberts (2000) offer a quotation from author Clifford Beers, in which he describes his experiences after his recovery from the Capgras delusion. When relatives came to see him, he said, "I was able to detect some slight difference in look or gesture or intonation of voice, and this was enough to confirm my belief that they were impersonators" (Beers, 1953, pp. 62-63). Beers thought he detected slight differences, as many patients do, but notice that during the delusional phase, he regarded these as confirmatory of a preexisting belief that the person he was looking at was a different person, some stranger who was "impersonating" his relative. One good example of this is the blind patient with Capgras' who said that the impostor's hand felt softer than his mother's (Rojo et al., 1991). It seems improbable that he determined that she was an impostor by feeling her hand. Rather, he believed she was an impostor prior to touching her hand, most likely when hearing her voice.

\section{EXECUTIVE PROCESSES}

According to the two-factor hypothesis of confabulation, once a person or limb is misidentified (Factor 1), the brains of the patients fail to employ executive processes to correct the error (Factor 2). What exactly are executive processes, though? Cognition requires both representations and processes for manipulating those representations - these latter are executive processes. Executive processes perform many different operations on representations. One clear illustration of executive processes at work managing representations occurs when we recall some past event from our lives. Your memory itself is just a huge collection of representations; executive processes must control the search and reconstruction processes that take place when we remember. Executive processes also control mental activity by allowing us to shift our focus from perception to memory or back, or to rearrange items held in working memory (e.g., in the digit span task, where a sequence of numbers is read out loud to the subject, who must then report the sequence in reverse order).

A great deal of what we normally call thinking, deciding, planning, and remembering is accomplished primarily by the brain's executive processes. One introspectively accessible measure of the amount of executive activity is our sense of mental effort. Increased mental effort correlates with increased usage of oxygen by executive areas, which is detectable by brain imaging. In such studies, tasks are devised that require the intervention of executive functions; brain activity is then monitored as the subject attempts the task. Most executive processes reside in the prefrontal lobes, including the 
dorsolateral frontal lobes on the side of the brain, the ventrolateral frontal lobes below them, the medial prefrontal lobes, on the inner surfaces of the two hemispheres, and the orbitofrontal lobes located on the brain's undersurface just above the eye sockets (Moscovitch \& Winocur, 2002). One area that is frequently active during effortful processing is the anterior cingulate, in the medial prefrontal cortex. The anterior cingulate is thought to play a role in resolving conflicts between routine actions that are not relevant to the present task, and novel actions that are relevant. It also activates strongly when the subject detects an error in his response (Carter, Botvinick, \& Cohen, 1999).

The executive processes can participate in the act of recognition itself, and they normally have the power to overrule our initial perceptual identifications. We all experience strange misperceptions at times, but we are able to correct them using executive processes. I believe I see my friend in a hotel lobby in Nairobi, but then I realise how improbable that is - this friend never travels, has no interest in Africa, etc.- so I tell myself that it is just someone who resembles my friend. The decision must be made at the executive level as to whether the presence in consciousness of a given representation truly means that the represented object is there. For example, the existence of phantom limbs involves an active egocentric representation of the missing limb, but at the executive level that activity is not taken as a veridical representation, mainly because the allocentric system strongly confirms the absence of the limb. Conversely, severing of the nerve to an arm can produce the impression that the arm is not there, due to the removal of somatosensation, which is part of the egocentric system. But executive processes are able to let the continued correctness of the external, allocentric representations of the arm overrule this impression: The arm is still there, merely numb, the patient concludes. The executive systems thus have the ability to let either the allocentric system or the egocentric system win out over the other, in the event of discord between them. When we first become aware of a person's presence, two different streams of processing, one egocentric and one allocentric, commence their work. In neurological patients, failure of either the allocentric stream or the egocentric stream, coupled with the relevant executive failure, should produce a confabulation if the patient is asked the right question.

\section{PROSOPAGNOSIA, COTARD'S SYNDROME, AND FRÉGOLI'S SYNDROME}

One way to test and further elucidate the representational hypothesis and its larger two-factor approach is to apply it to other syndromes in which recognition of persons fail. Neurological patients with prosopagnosia can no 
longer visually recognise the people they know, and their faces do not look familiar to the patient, but the patients continue to attribute the same personalities and other mental traits to them once they recognise them, typically by the sounds of their voices. Prosopagnosics can sometimes recognise people using specific visual cues, such as a person's distinctive nose or ears, or even the type of glasses or tie someone typically wears. For the prosopagnosic, the familiar face is not present, but the person is; once the patient hears his mother speak, he recognises her, and will treat her as his mother. For the Capgras' patient, the familiar face is present, but the person is not. The Capgras' patient's allocentric system is intact, but his normal egocentric representation of that person is damaged or inaccessible. The Capgras' patient's relevant executive processes are malfunctioning, and this prevents him from realising how implausible the impostor claim is and rejecting it. The typical prosopagnosic does not have executive damage, but according to the hypothesis described here, a prosopagnosic with executive damage should confabulate when asked to identify people. The two patients of Rapcsak, Polster, Comer, and Rubens (1994) seem to fit this profile. They were both unable to recognise familiar faces, and when asked to identify faces in photographs, they employed the style typically seen in prosopagnosics of attempting to identify faces by focusing on distinctive features. The use of this strategy, together with executive failure, caused the patients to confabulate that unfamiliar people were familiar, because the unfamiliar person shared some facial feature with the familiar person. One of the patients pointed to a fellow patient on the ward, for instance, and exclaimed, "There's my father! I'd recognise that hooked nose anywhere!" The authors seem to favour a twofactor approach, noting that, "the frontal lobes are also likely to be responsible for detecting and resolving potential ambiguities arising in connection with the operations of perceptual recognition systems" (Rapscak et al., 1994, p. 577). They further observe that, "the dysfunction of the decision making process in our patients was evidenced by the fact that they rarely if ever attempted to verify the correctness of their initial impressions regarding a person's identity. Instead, they seemed to accept the output generated by the impaired face recognition system unconditionally." We might call this syndrome dysexecutive prosopagnosia. It causes misidentifications based on superficial similarities of facial features that patients lack the executive processes to correct.

The patient with Cotard's syndrome says that he is dead, hollow, or empty. These patients perceive their own body and face well enough, but see no mind at home there, rather like a dense neurological version of depersonalisation. Cotard's original patient said that she had "no brain, nerves, chest, or entrails, and was just skin and bone" (Berrios \& Luque, 1995). One Cotard's patient described "feeling nothing inside" (Wright, Young, \& Hellawell, 1993); another patient "felt that her brain was dead" 
(Young, Leafhead, \& Szulecka, 1994). Although strictly speaking, Cotard's syndrome is not a misidentification syndrome, since the person is correctly identified but thought to be dead, an explanation of it can be derived from the account given here. According to the representational hypothesis, Cotard's syndrome is caused by complete destruction of the mindrepresenting part of the egocentric representation system. Patients with Cotard's and Capgras' for themselves recognise themselves externally, but attribute either no mind at all to themselves, and hence speak of themselves as "dead" or "robots" (Cotard's), or they perceive themselves to have strange, unknown minds (Capgras'). Some Capgras' patients see an unfamiliar mind behind the face in photos of themselves or even in their own mirror images, and hence may speak of the persons seen in photos or mirrors as impostors. The Frégoli's syndrome patient sees a certain significant person as somehow inhabiting several different bodies. According to the representational hypothesis, what happens in Frégoli's syndrome is that the patient's egocentric representation of a familiar person is paired with allocentric representations of unfamiliar faces and bodies. This produces in the patient the impression of a single familiar person disguising herself as a succession of strangers.

The crucial posterior damage site for misidentification syndromes (in addition to prefrontal damage causing executive failures) may be a cortical area just inferior to the supramarginal gyrus, the temporoparietal junction (TPJ). Two Cotard's patients studied by Young and his colleagues (Young et al. 1994; Young, Robertson, Hellawell, de Pauw, \& Pentland, 1992) had temporoparietal contusions along with bilateral frontal damage. The Capgras' patient of Staton et al. (1982, p. 26) showed "a discrete area of moderate atrophy deep in the [right] posterior-superior temporal lobe at the temporo-parietal junction". Similarly, a Capgras' patient seen by Johnson and Raye (1998) had a right temporoparietal hematoma. A Frégoli's patient described by Feinberg, Eaton, Roane, and Giacino (1999) also had damage at the temporoparietal junction. The temporoparietal junction has been found to be active during several "theory of mind" tasks, in which subjects attempt to understand the actions and motives of others. In a typical task, the brain of a subject is scanned as she observes people performing certain actions, or displaying certain emotions. The right TPJ's activity level was observed to be high when "participants read stories that describe a character's beliefs but low during stories containing other socially relevant information" (Young \& Saxe, 2009). It is also relevant that the right TPJ activates more strongly when the target person has beliefs that are known by the subject to be false (Young \& Saxe, 2009). Saxe (2006, p. 235) describes the TPJ as an "area for representing mental states" that responds selectively to "the attribution of mental states" (Saxe \& Wexler, 2005, p. 1391) and 
plays a role in developing an "integrated impression" of people (Saxe \& Wexler, 2005, p. 1396).

There are two gaps in the representational hypothesis which still need filling, however. First, the findings of Saxe and others concern real-time attributions of mental states to strangers, whereas at least some of the misidentification syndromes involve people very well known to the patient. A second gap is that the mindreading system findings concern real-time, single events of mental state attribution, whereas I am postulating that these events are accumulated in a type of memory into a mental representation of someone's mind. A first step in meeting this objection is to point out that there is evidence of a TPJ link to the autobiographical memory system; Maguire (2001) and Fink et al. (1996) found TPJ activity during a task in which subjects recalled emotional autobiographical events. There is still a gap here, though, in that autobiographical memory is about me, whereas I am postulating that there is a related type of memory centred on significant other people; i.e., that the ego in the egocentric position of the autobiographical memory system is not always that of the owner of that system.

Recall that the egocentric representation represents not merely a mind, but a mind housed in a body, which is itself situated in an environment. We use this system to understand the intentional actions of people in environments. Saxe notes that the TPJ is also "selectively recruited for determining how the spatial relations between two objects would appear from a character's point of view versus the subject's own position" (2006, p. 236). The role in computing perspective differences and the role in computing mental states may actually involve different but adjacent portions of the TPJ. Aichhorn, Perner, Kronbichler, Staffen, and Ladurner (2006) recommend that the TPJ be divided into two areas, arguing that its dorsal portion is "responsible for representing perspective differences and making behavioural predictions", whereas its ventral part-along with the medial prefrontal cortex - is responsible for "predicting behavioural consequences" of another person's mental states. The egocentric system may well have other modes, including what we might call an alternative self-mode, which we use to imagine ourselves in possible scenarios. Blanke and his colleagues found that one can produce a vivid out-of-body experience involving what they refer to as an "abnormal egocentric visuospatial perspective" (Blanke et al., 2005) by electrically stimulating the temporoparietal junction (Blanke \& Arzy, 2005), something that again is consistent with its use to represent not only our own location in space, but also locations that we are not currently in. Notice that even though these out-of-body experiences are vivid and realistic, the person does not actually believe that he is, e.g., flying around the room. According to the two-factor approach, this is because her executive processes are intact and are able to overrule the experience. This predicts, however, that it these experiments were tried on someone with the 
right executive processes damaged, she would actually take the experience to be veridical. Recent research on what is called the brain's default network supports the idea that a single large system functions to represent both ourselves when navigating through space or imagining ourselves in other possible situations, as well as functioning to achieve mindreading tasks when our attention is directed at others, and to achieve autobiographical memory (Buckner \& Carroll, 2007). This would also make sense of the finding by Mitchell (2008) that the right TPJ is active both when we are attributing beliefs to others and when we are reorienting our attention to a different location in space: Normally the TPJ represents our space, but sometimes it represents the simulated space of a person of interest.

\section{EPISODIC MEMORIES OF OTHERS}

A person's episodic memories are memories of that person from her point of view. The representations that are stored in episodic memory are egocentric because they represent events as we experienced them; hence they are also called autobiographical memories. Autobiographical episodic memories combine several different subrepresentations including representations of our bodies moving through different spaces and environments and representations of the people and objects we have significant interactions with. We carefully represent each aspect of a particularly significant interaction, exactly what was said, and in which tone of voice. In addition to representations of emotions, episodic memories may also contain representations of other conscious states, such as our thoughts, motives, and intentions at the time of the event. Hence, a full autobiographical memory representation is of a person with a conscious mind, moving through space, interacting with people and objects.

The episodic memory system is also able to aggregate its information into our existing concepts of important people and things. Once this information enters the system of concepts it becomes part of the semantic memory system also, and is then accessible to the process of thinking. Thus, the episodic memory system can feed the semantic memory system. For instance, if I travel to Paris, the episodic memories I amass as I see important sites in the city also add information to my semantic representation of Paris, the Eiffel Tower, the Arc de Triomphe, etc. All of this information tends to be either semantic/conceptual or allocentric in form, but I suggest that the egocentric realm has its own ability to aggregate its representations into a full-blown simulation of persons' minds. As I accumulate information about someone over the course of many interactions with her, I also accumulate information about her thoughts, moods, and emotions, using the egocentric representations system in other-mode. We 
might call such accumulated memories, "biographical memories". They contain information that is extremely valuable to us, so I suspect that we do not discard it, but rather carefully organise and maintain it, in the form of accumulations of simulated mental states that are representations of the minds of the significant people in our lives. If this is right, our full representation of a significant person contains an allocentric component with representations of how he looks and sounds, and an egocentric representation of his mind, body, and environments from his viewpoint. Our awareness of the minds of others when the egocentric system is operating in other-mode seems to be nonexplicit and faint in our minds. Perhaps this is a reason why distinguishing whether an emotion or a simulation of a mind is missing (as may happen in Capgras' syndrome) is difficult for the patients. One hypothesis for why the activity level of the egocentric system needs to be low when it is operating in other-mode is that vivid conscious representation leads to actual external actions, not merely to represented actions, in much the same way that the dreaming mind malfunctions during REM sleep disorder, when perceptions that are merely dreamed cause real actions. Simulations cannot fully and explicitly employ this representation system without danger of causing real actions, with potentially disastrous consequences.

If correct, this view implies that we possess representations of specific individual minds, but surely we also have some ability to understand the minds of strangers. There is also evidence that we possess a set of generic mind representations that we can employ with people who we don't know well enough yet to have created a mind representation of. It seems obvious that we create generic representations of significant things. All of my episodic memories of visits to grocery stores, for instance, organise themselves into generic memories of certain grocery store types, which I access when I decide where to go to purchase certain foods, or where to look once I'm in a grocery store. I employ different accumulations of autobiographical memories if I am in a huge chain store, a country grocery, or the corner convenience mart. If the Capgras' patient has lost his representation of his father's individual mind, but uses a generic representation when he now looks at him, this is precisely what would produce the impression of an impostor-his father's body and face, but alloyed with the mind of some other, unfamiliar person. On this hypothesis, then, when both individual and generic egocentric representations are unusable, Cotard's syndrome results. The patient can only represent himself externally, using the allocentric system, and this causes him to see himself as empty and without a mind. This can also explain why some patients, such as that of Wright et al. (1993), alternate between Cotard's and Capgras' syndromes: The patient's egocentric representations are inaccessible, while his generic egocentric representations are intermittently on- and offline, perhaps due to irregular blood flow, or to remapping of the damaged 
neural networks. When they are functioning, the patient has Capgras' syndrome, when they are not functioning, he has Cotard's syndrome.

One objection to this account is that it locates the problem in the misidentification syndromes at too high a level. Misidentification is much closer to being a lower level perceptual problem than a higher level problem representing the mind of the target person, according to this objection. Think of what it would be like, however, if you became convinced that someone you knew well had been replaced by an impostor. As you see her coming towards you, you recognise the familiar face, and conclude that it is your friend. But when she becomes closer and begins to speak to you, something seems wrong. As you continue to interact with her, it seems to you that she doesn't have the same beliefs, thoughts, moods, and preferences of the person you originally knew. You start to get the impression that this is actually someone else. If you were a normal person, with intact executive processes, you would not allow yourself to form this conclusion, however. You would be much more likely to conclude that your friend has undergone some sort of change in personality, or even to attribute the problem to yourself, concluding perhaps that you hadn't really known her as well as you thought you did. If this account is true to the phenomenology of Capgras' syndrome, the problem is not immediately perceptual. It is also important not to tie Capgras' too closely to visual perception at least, since as noted earlier it has been observed in blind people (Dalgalarrondo, Fujisawa, \& Banzato, 2002; Hermanowicz, 2002; Rojo et al., 1991).

\section{ASOMATOGNOSIA AND PHANTOM LIMBS}

If Capgras' syndrome is in one sense the opposite of Frégoli's syndrome, then what is the opposite of asomatognosia? The vast majority of people who undergo amputation of a limb have a clear sensation that the limb is still there - a phantom limb. Their experience of the limb seems to be the same as before. They experience it as being in a certain position, as being hot or cold, as being in pain, as being paralysed, and sometimes even as moving in response to their intentions, for instance reaching out to shake hands with someone (Ramachandran \& Hirstein, 1998). The asomatognosic's arm is there, but it seems to him that it is not; the phantom limb patient's arm is not there, but it seems to him that it is. The arms of phantom limb patients feel the same from the inside, as it were, but obviously do not look the same on the outside. Asomatognosia is just the opposite: The patient's limb looks the same externally but lacks certain internal sensations. There is a great difference in conviction, of course; the asomatognosic is certain that the arm is not his arm, whereas the phantom limb patient is able to overrule the vivid impression of the arm's presence and acknowledge that his limb is gone. 
If the two-factor hypothesis of confabulation is correct, however, the difference between the two is that the asomatognosic has damaged prefrontal processes - processes that should prevent his odd impression from establishing itself as a belief, and this explains the difference in conviction. Those cases of asomatognosia in which the patient claims that his arm is dead may be the bodily analogue of Cotard's syndrome in the case of mindreading. In both cases, a complete destruction of the relevant portions of the egocentric representation system causes the patient to feel that his arm, or he himself, is empty or dead. There is an asymmetry here, however: With Capgras' or Cotard's syndrome, the representation of the entire mind is compromised, whereas in asomatognosia, a representation of only a portion of the body is compromised. This may be due to a difference in the sort of representations the brain employs. Body representations occur in the form of somatotopic maps, spread out over cortical areas, so that damage might affect just a portion of the map. Perhaps mind representations are in some more holistic form, so that damage to a portion of them affects the entire representation.

What would a phantom limb patient with compromised executive processes say about his limb? There is an analogy here with dysexecutive prosopagnosia in the realm of limbs. Amputee patients with phantom limbs have not normally also sustained brain damage, but if a person lost a limb and damaged the relevant frontal processes, would he actually deny that his limb was gone? The Capgras' patient DS described in Hirstein and Ramachandran (1997) was just such a person. His right arm needed to be amputated, just below the elbow, after a car accident in which he also sustained serious brain damage. At several points in our interactions with him, he denied that his arm was gone.

\section{MISIDENTIFICATION AND THE THIRD VISUAL STREAM}

In spite of not being able to consciously recognise familiar people, prosopagnosics will register a larger average skin-conductance response (SCR) to familiar faces than to unfamiliar faces. Bauer (1984) and Ellis and Young (1990) suggested that Capgras' syndrome is the mirror-image of prosopagnosia, and hypothesised that Capgras' patients would lack the normal SCR to familiar faces, and this was later verified in several patients (Ellis, Young, Quayle, \& de Pauw, 1997; Hirstein \& Ramachandran, 1997). Prosopagnosics typically show damage to the fusiform gyrus, on the undersurface of the temporal lobes, so it was generally thought that damage to this more ventral route destroys the ability to recognise familiar faces, while some other processing stream was intact, and still able to produce an SCR to the seen faces. It is not clear where the other 
processing stream is, however. Bauer initially suggested that the SCR route was in the dorsal cortex, but this seemed implausible given that this cortex specialises not in face recognition, but in representing the body, and in coordinating the computations needed for spatial navigation, reaching for objects, and such tasks.

In 2003, Rizzolatti and Mattelli proposed that the traditional division of visual streams leaving the occipital lobe into a ventral and a dorsal one (Ungerleider \& Mishkin, 1982) is inadequate, and that the dorsal stream of visual processing should be divided into two separate streams which they call the dorsodorsal stream, and the ventrodorsal stream. The dorsodorsal stream has all of the characteristics traditionally attributed to the dorsal stream: It terminates in the superior parietal lobe and functions to provide the information required to execute actions involving, e.g., reaching for nearby objects. The idea of a ventrodorsal stream is a new concept, though, and that stream has been found to have some interesting characteristics. Area PF in the rhesus monkey, which corresponds to the supramarginal gyrus in humans, is the primary recipient area of visual input for this stream. Area PF is now known to contain mirror neurons, neurons that respond when the subject executes a particular, e.g., arm action, or when the subject sees another person execute that same action (Rizzolatti \& Craighero, 2004). In my earlier terminology, $\mathrm{PF}$ is able to operate in both self-mode and othermode. This raises the intriguing possibility that the recipient areas of the ventrodorsal stream are the ones damaged in Capgras' patients, as well as other misidentification patients.

The mindreading system and the mirror neuron system are different systems, however, and several writers have pointed out that they are disjoint (Decety \& Lamm, 2006; Jackson \& Decety, 2004; Saxe, 2005). The mindreading system is currently thought to consist of the left and right TPJ, an area of dorsomedial prefrontal cortex, an area of the superior temporal sulcus (STS), and a portion of the posterior cingulate gyrus (Saxe, 2005). The mirror neuron system consists of three cortical areas, one that corresponds to PF, a portion of the superior temporal sulcus, and a frontal component, located in the ventral portion of Brodmann's Area 6 (Rizzolatti \& Craighero, 2004). The STS does not contain mirror neurons, but does respond to biological motion, i.e., movements by living organisms, including human eye movements (Hoffman \& Haxby, 2000; Puce \& Perrett, 2003). Perhaps the superior temporal sulcus links the mindreading and mirror systems. One would expect to find such a link, on the hypothesis that we use the mirror neuron system to understand what action a person is performing, leading naturally to the use of the mindreading system to understand the beliefs, motives, and intentions behind the action. 


\section{CONCLUSION}

The brain's right hemisphere appears to contain areas, such as the supramarginal gyrus and the temporoparietal junction just below it, that serve the dual function of representing ourselves on certain occasions, and other people on other occasions. I suggest that areas such as the supramarginal gyrus and the TPJ, working in concert with interconnected areas in the temporal and prefrontal lobes, are responsible for the sense of oneself as an embodied being with a mind situated in an environment. Out-of-body experiences, for instance, contain representations of what one's phenomenology, one's mental life, would be like, as well the changes in one's body and its environment. When we understand the intentional actions of others, these areas serve as an egocentric representation of them.

The debates here raise deeper issues about how we represent things and people, independently of the properties that they have only contingently. Descartes (1632/1967) famously noted that a ball of wax can change every one of its properties, its shape, colour, texture, smell, and hardness, when brought near a flame and melted, and yet we still represent it as the same thing. Philosophers in the middle ages spoke of things as containing a sort of core essence that they called a "haecceity", that maintains their identities despite changes in their properties. Perhaps haecceities or something like them exist not in things themselves (indeed, where would they be, and what sort of material existence could they have?) but rather in our brains. Perhaps the central "ego" in the egocentric system functions as a sort of haecceity, in that it is tied to the identity of a specific person (which may vary over time), no matter what the other parts of the egocentric system represent, while itself having no representational content.

The account here, if correct, brings the misidentification syndromes and asomatognosia into line with the rest of the confabulation syndromes by showing how they also fall under a two-factor hypothesis. Confabulation is caused by two events: (1) Damage to some perceptual or mnemonic process in the posterior of the brain, typically the cortex; and (2) damage to some prefrontal executive process that monitors and can correct the output of that perceptual or mnemonic process. In the case of asomatognosia, the posterior lesion tends to occur in the inferior parietal lobe, often in the supramarginal gyrus. The lesion that causes misidentifications of people seems to be just below that one, in the temporoparietal junction. We build large, detailed representations of the minds of those close to us, according to this hypothesis. We create these representations so automatically, and they operate so subtly, that when they are damaged we have trouble understanding what has happened. Capgras' patients perceive a 
familiar face and body, but inhabited by an unfamiliar mind. With no executive processes to resolve the contradiction, the odd impression forms into a delusional belief which, when expressed, becomes a confabulation about an impostor.

\section{REFERENCES}

Aichhorn, M., Perner, J., Kronbichler, M., Staffen, W., \& Ladurner, G. (2006). Do visual perspective tasks need theory of mind? Neuroimage, 30, 1059-1068.

Babinski, J. (1914). Contribution a l'etude des troubles mentaux dans l'hemiplegie organique cerebrale (anosognosie). Revue Neurologique (Paris), 27, 845-848.

Bauer, R. M. (1984). Autonomic recognition of names and faces in prosopagnosia: A neuropsychological application of the Guilty Knowledge Test. Neuropsychologia, 22, 457-469.

Bauer, R. M. (1986). The cognitive psychophysiology of prosopagnosia. In H. Ellis, M. A. Jeeves, F. Newcombe, \& A. Young (Eds.), Aspects of face processing. (pp. 235-267) Dordrecht, The Netherlands: Nijhoff.

Beers, C. W. (1953). A mind that found itself: An autobiography (7th ed.). New York: Doubleday.

Berlyne, N. (1972). Confabulation. British Journal of Psychiatry, 120, 31-39.

Berrios, G. E., \& Luque, R. (1995). Cotard's syndrome: Analysis of 100 cases. Acta Psychiatrica Scandia, 91, 185-188.

Berti, A., Bottini, G., Gandola, M., Pia, L., Smania, N., Stracciari, A., et al. (2005). Shared cortical anatomy for motor awareness and motor control. Science, 309, 488-491.

Bisiach, E., \& Geminiani, G. (1991). Anosognosia related to hemiplegia and hemianopia. In G. P. Prigatano \& D. L. Schacter (Eds.), Awareness of deficit after brain injury: Clinical and theoretical issues. (pp. 17-39) Oxford, UK: Oxford University Press.

Blanke, O., \& Arzy, S. (2005). The out-of-body experience: Disturbed self-processing at the temporo-parietal junction. Neuroscientist, 11, 16-24.

Blanke, O., Mohr, C., Michel, C. M., Pascual-Leone, A., Brugger, P., Seeck, M., et al. (2005). Linking out-of-body experience and self processing to mental own-body imagery at the temporoparietal junction. Journal of Neuroscience, 25, 550-557.

Breen, N., Caine, D., Coltheart, M., Hendy, J., \& Roberts, C. (2000). Towards an understanding of delusions of misidentification: Four case studies. In M. Coltheart \& M. Davies (Eds.), Pathologies of belief. (pp. 75-110) Oxford, UK: Blackwell.

Buckner, R. L., \& Carroll, D. C. (2007). Self-projection and the brain. Trends in Cognitive Sciences, 11(2), 49-57.

Capgras, J., \& Reboul-Lachaux, J. (1923). L'illusion des "sosies" dans un délire systématisé chronique. Bulletin de la Société Clinique de Médecine Mentale, 11, 6-16. Reprinted in H. D. Ellis, J. Whitley, \& J. P. Luauté (Eds.). (1994). Delusional misidentifications: The three original papers on the Capgras, Fregoli and intermetamorphosis delusions. History of Psychiatry, 5, $117-146$.

Carter, C. S., Botvinick, M. M., \& Cohen, J. D. (1999). The contribution of the anterior cingulate cortex to executive processes in cognition. Reviews in the Neurosciences, 10, 49-57.

Coltheart, M. (2007). The 33rd Bartlett lecture: Cognitive neuropsychiatry and delusional belief. Quarterly Journal of Experimental Psychology, 60, 1041-1062.

Critchley, M. (1974). Misoplegia or hatred of hemiplegia, Mt. Sinai Journal of Medicine, 41, 82-87.

Dalgalarrondo, P., Fujisawa, G., \& Banzato, C. E. M. (2002). Capgras syndrome and blindness: Against the prosopagnosia hypothesis. Canadian Journal of Psychiatry, 47(4), 387-388. 
Davies, M., Coltheart, M., Langdon, R., \& Breen, N. (2001). Monothematic delusions: Toward a two-factor account. Philosophy, Psychiatry, and Psychology, 8(2-3), 133-158.

Davies, M., Davies, A. A., \& Coltheart, M. (2005). Anosognosia and the two-factor theory of delusions. Mind and Language, 20(2), 209-236.

Decety, J., \& Lamm, C. (2006). Human empathy through the lens of social neuroscience. Scientific World Journal, 6, 1146-1163.

Descartes, R. (1967). Meditations on first philosophy. Trans. E. Haldane \& D. Ross. Cambridge, UK: Cambridge University Press. (Original work published 1632)

Ellis, H. D., \& Young, A. W. (1990). Accounting for delusional misidentifications. British Journal of Psychiatry, 157, 239-248.

Ellis, H. D., Young, A. W., Quayle, A. H., \& de Pauw, K. W. (1997). Reduced autonomic responses to face in Capgras delusion. Proceedings of the Royal Society of London, Series B, 264, 10851092.

Feinberg, T. E. (2001). Altered egos: How the brain creates the self. Oxford, UK: Oxford University Press.

Feinberg, T. E. (2006). Our brains, our selves. Daedelus, Fall, 72-80.

Feinberg, T. E. (2009). Confabulation and ego functions: The ego dysequilibrium theory. In W. Hirstein (Ed.), Confabulation: Views from neuroscience, psychiatry, psychology, and philosophy (pp. 91-108). Oxford, UK: Oxford University Press.

Feinberg, T. E., DeLuca, J., Giacino, J. T., Roane, D. M., \& Solms, M. (2005). Right hemisphere pathology and the self: Delusional misidentification and reduplication. In T. E. Feinberg \& J. P. Keenan (Eds.), The lost self: Pathologies of brain and identity. Oxford, UK: Oxford University Press.

Feinberg, T. E., Eaton, L. A., Roane, D. M., \& Giacino, J. T. (1999). Multiple Fregoli delusions after brain injury. Cortex, 35, 373-387.

Feinberg, T. E., Haber, L. D., \& Leeds, N. E. (1990). Verbal asomatognosia. Neurology, 40, 13911394.

Feinberg, T. E., \& Roane, D. M. (1997). Anosognosia, completion and confabulation: The neutralpersonal dichotomy. Neurocase, 3, 73-85.

Fine, C. (2006). A mind of its own: How your brain distorts and deceives. New York: W. W. Norton.

Fink, G. R., Markowitsch, H. J., Reinkemeier, M., Bruckbauer, T., Kessler, J., \& Heiss, W. D. (1996). Cerebral representation of one's own past: Neural networks involved in autobiographical memory. Journal of Neuroscience, 16, 4275-4282.

Förstl, H., \& Beats, B. (1992). Charles Bonnet's description of Cotard's delusion and reduplicative paramnesia in an elderly patient. British Journal of Psychiatry, 160, 416-418. (Original work published 1788)

Fotopoulou, A. (2009). Disentangling the motivational hypotheses in confabulation. In W. Hirstein (Ed.), Confabulation: Views from neuroscience, psychiatry, psychology, and philosophy (pp. 263290). Oxford, UK: Oxford University Press.

Fotopoulou, A. (2010). The affective neuropsychology of confabulation and delusion. Cognitive Neuropsychiatry, 15(1/2/3), 38-63.

Frazer, S. J., \& Roberts, J. M. (1994). Three cases of Capgras' syndrome. British Journal of Psychiatry, 164, 557-559.

Goldman, A. (2006). Simulating minds: The philosophy, psychology, and neuroscience of mindreading. Oxford, UK: Oxford University Press.

Hermanowicz, N. (2002). A blind man with Parkinson's disease, visual hallucinations, and Capgras syndrome. Journal of Neuropsychiatry and Clinical Neuroscience, 14(4), 462-463.

Hirstein, W. (2005). Brain fiction: Self-deception and the riddle of confabulation. Cambridge, MA: MIT Press. 
Hirstein, W., \& Ramachandran, V. S. (1997). Capgras syndrome: A novel probe for understanding the neural representation of the identity and familiarity of persons. Proceedings of the Royal Society of London, Series B, 264, 437-444.

Hoffman, E. A., \& Haxby, J. V. (2000). Distinct representations of eye gaze and identity in the distributed human neural system for face perception. Nature Neuroscience, 3, 80-84.

Jackson, P. L., \& Decety, J. (2004). Motor cognition: A new paradigm to study self-other interactions. Current Opinion in Neurobiology, 14, 259-263.

Johnson, M. K., \& Raye, C. L. (1998). False memories and confabulation. Trends in Cognitive Sciences, 2, 137-145.

Langdon, R., \& Bayne, T. (2010). Delusion and confabulation: Mistakes of perceiving, remembering and believing. Cognitive Neuropsychiatry, 15(1/2/3), 319-345.

Langdon, R., \& Coltheart, M. (2000). The cognitive neuropsychology of delusions. Mind and Language, 15, 184-218.

Lettsom, J. C. (1789). History of some of the effects of hard drinking. London: Henry Fry.

Maguire, E. A. (2001). Neuroimaging studies of autobiographical memory. In A. Baddeley, J. Aggleton, \& M. A. Conway (Eds.), Episodic memory: New directions in research (pp. 165180). Oxford, UK: Oxford University Press.

Maher, B. A. (1988). Anomalous experience and delusional thinking: The logic of explanations. In T. F. Oltmanns \& B. A. Maher (Eds.), Delusional beliefs (pp. 15-33). Chichester, UK: Wiley.

McKay, R., \& Kinsbourne, M. (2010). Confabulation, delusion, and anosognosia: Motivational factors and false claims. Cognitive Neuropsychiatry, 15(1/2/3), 288-318.

Metcalf, K., Langdon, R., \& Coltheart, M. (2007). Models of confabulation: A critical review and a new framework. Cognitive Neuropsychology, 24(1), 23-47.

Mitchell, J. P. (2008). Activity in the right temporo-parietal junction is not selective for theory-ofmind. Cerebral Cortex, 18, 262-271.

Moscovitch, M., \& Winocur, G. (2002). The frontal cortex and working with memory. In D. T. Stuss \& R. T. Knight (Eds.), Principles of frontal lobe functions (pp. 188-209). Oxford, UK: Oxford University Press.

Nielsen, J. M. (1938). Gerstmann syndrome; finger agnosia, agraphia, confusion of right and left, acalculia; comparison of this syndrome with disturbances of body scheme resulting from lesions of right side of brain. Archives of Neurological Psychiatry, 39, 536-560.

Puce, A., \& Perrett, D. (2003). Electrophysiology and brain imaging of biological motion. Philosophical Transactions of the Royal Society of London, Series B: Biological Sciences, 358, 435-445.

Ramachandran, V. S., \& Hirstein, W. (1998). The perception of phantom limbs: The D. O. Hebb lecture. Brain, 121, 1603-1630.

Rapcsak, S. E., Polster, M. R., Comer, J. F., \& Rubens, A. B. (1994). False recognition and misidentification of faces following right hemisphere damage. Cortex, 30, 565-583.

Rizzolatti, G., \& Craighero, L. (2004). The mirror neuron system. Annual Reviews of Neuroscience, 27, 169-192.

Rizzolatti, G., \& Mattelli, M. (2003). Two different streams form the dorsal visual system: Anatomy and function. Experimental Brain Research, 153, 146-157.

Rojo, V. I., Caballero, L., Iruela, L. M., \& Baca, E. (1991). Capgras' syndrome in a blind patient. American Journal of Psychiatry, 148(9), 1271-1272.

Saxe, R. (2005). Against simulation: The argument from error. Trends in Cognitive Sciences, 9, 174-179.

Saxe, R. (2006). Uniquely human social cognition. Current Opinion in Neurobiology, 16, 235-239.

Saxe, R., \& Wexler, A. (2005). Making sense of another mind: The role of the right temporoparietal junction. Neuropsychologia, 43, 1391-1399. 
Signer, S. F. (1994). Localization and lateralization in the delusion of substitution. Psychopathology, 27, 168-176.

Silva, J. A., \& Leong, G. B. (1994). Delusions of psychological change of the self. Psychopathology, 27, 285-290.

Staton, R. D., Brumback, R. A., \& Wilson, H. (1982). Reduplicative paramnesia: A disconnection syndrome of memory. Cortex, 18, 23-36.

Stone, T., \& Young, A. W. (1997). Delusions and brain injury: The philosophy and psychology of belief. Mind and Language, 12, 327-364.

Turner, M., \& Coltheart, M. (2010). Confabulation and delusion: A common monitoring framework. Cognitive Neuropsychiatry, 15(1/2/3), 346-376.

Ungerleider, L. G., \& Mishkin, M. (1982). Two visual streams. In D. J. Ingle, M. A. Goodale, \& R. J. W. Mansfield (Eds.), Analysis of visual behavior (pp. 549-586). Cambridge, MA: MIT Press.

Vié, J. (1930). Un trouble de l'identification des personnes: l'illusion des sosies. Annals of Medical Psychology, 88, 214-237.

Weinstein, E. A. (1991). Anosognosia and denial of illness. In G. P. Prigatano \& D. L. Schacter (Eds.), Awareness of deficit after brain injury: Clinical and theoretical issues (pp. 240-257). Oxford, UK: Oxford University Press.

Wright, S., Young, A. W., \& Hellawell, D. J. (1993). Sequential Cotard and Capgras delusions. British Journal of Clinical Psychology, 32, 345-349.

Young, A. W., Leafhead, K. M., \& Szulecka, T. K. (1994). Capgras and Cotard delusions. Psychopathology, 27, 226-231.

Young, A. W., Robertson, L. H., Hellawell, D. J., de Pauw, K. W., \& Pentland, B. (1992). Cotard delusion after brain injury. Psychological Medicine, 22, 799-804.

Young, L., \& Saxe, R. (2009). An fMRI investigation of spontaneous mental state inference for moral judgment. Journal of Cognitive Neuroscience, 21(7), 1396-1405. 